\title{
Regiospecific Ring-Opening of Unsymmetrical Epoxides to the Corresponding Less Substituted Alcohols by Newly-Devised Meerwein-Ponndorf-Verley Type Reagents
}

\author{
Jin Soon Cha ${ }^{\dagger}$ \\ Abstract \\ A newly-devised Meerwein-Ponndorf-Verley (MPV) reagents, such as diisobutylacetoxyalanes and \\ diisobutylmethanesulfonylalanes, achieved a clean conversion of unsymmetrical epoxides to the corresponding less \\ substituted alcohols. This review covers the recent developments for such a regiospecific ring-opening reaction of \\ epoxides.
}

Key word : Ring-opening, Epoxide, Meerwein-ponndorf-verley, Alcohol

\section{Introduction}

The Meerwein-Ponndorf-Verley (MPV) reaction has been known as a mild and specific method of reducing carbonyl compounds since 1925 . However, the discovery of sodium borohydride ${ }^{[1]}$ in 1942 and of lithium aluminum hydride ${ }^{[2]}$ in 1945 brought about a revolutionary change in procedures for the reduction of functional groups in organic molecules. Today, for instance, in dealing with the problem of reducing an aldehyde or ketone function, the synthetic organic chemist will rarely undertake to use such a conventional technique. Moreover, the advent of a variety of modified metal hydride reagents possessing a high degree of selectivity has made it possible to have a broad spectrum of reagents for selective reductions. However, recent developments in the design of new type of MPV reagent and in its application for the reduction of organic functional groups such as epoxy compounds led us to reassess its applicability and selectivity in organic synthesis. Consequently, it appears of interest to review the regiospecific reaction of epoxides by the newly-developed MPV reactions.

Department of Chemistry, Yeungnam University, Gyongsan 712-749, Korea

${ }^{\dagger}$ Corresponding author : jscha@yu.ac.kr

(Received : June 2, 2012, Revised : June 20, 2012,

Accepted : June 24, 2012)

\section{Mechanistic Consideration of the MPV Reactions}

\subsection{Aluminum Reagents}

The MPV reaction with aluminum isoproxide is reversible, but the equilibrium can be shifted to the point of complete reduction by removal of the acetone with a stream of dry nitrogen or by slow distillation. The equilibrium proceeds by an oxidation - reduction reaction of a carbinol - carbonyl pair accelerated by aluminum alkoxide.

The generally accepted mechanism for MPV reactions proceeds via a complex in which both the carbonyl compound and the reducing alcohol are bound to the metal ion as shown in Scheme 1 for the reaction of aluminum isopropoxide. The carbonyl is then activated upon coordination to $\mathrm{Al}$ (III), followed by a hydride transfer from the alcoholate to the carbonyl group via a six-membered transition state. Likewise, the mechanism of the reaction of carbonyl compounds with triisobutylaluminum (TIBA) involves hydride shift from the $\beta$-carbon atom and thus proves to be very similar to the MPV reduction process (Scheme 2).

\subsection{Boron Reagents}

As in the report by Mikhailov ${ }^{[3]}$ on the reaction of trialkylboranes with benzaldehyde at elevated temperatures, the rate of the elimination of an olefin from a 
<smiles>[R]C([R])=O</smiles><smiles>CCCO[Al](OC(C)C)OC(C)C</smiles><smiles>C=CC</smiles><smiles>C=C=C</smiles>

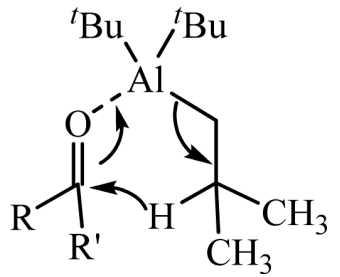

Scheme 2<smiles></smiles>

Scheme 3

trialkylborane increases with increase in the number of methyl groups on the $\beta$-carbon atom, which indicates reaction with elimination of a hydride ion via a cyclic electron transfer (Scheme 3).

\subsection{Appearance of New MPV Type Reagents}

We usually say that MPV reduction is performed with aluminum isopropoxide as a catalyst and isopropyl alcohol as a hydride source. From the mechanistic point of view as depicted in Scheme 19, however, there are two points to be considered. One is that the actual reduction takes place by virtue of the $\beta$-hydrogen transfer from isopropoxy group attached to $\mathrm{Al}$ atom of catalyst. This means that isopropyl alcohol does not participate at the key step of reduction: isopropyl alcohol acts as an isopropoxy group source which substantially provides a hydride. The other is that MPV

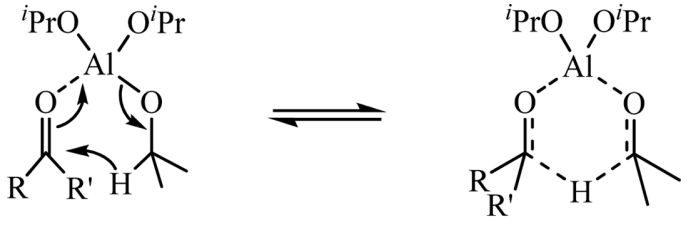<smiles>[R]C([R])(C)O[Al](O[Ga])(OC(C)C)OC(C)C</smiles><smiles>C=C=C</smiles>

cheme 1

reaction is reversible: acetone formed accelerates the reversible reaction.

Practically, there have encountered some problems in this reaction: the reduction usually proceeds sluggishly even with an excess catalyst and requires the removal of acetone in order to shift the equilibrium in the desired direction. Therefore, efforts to devise new catalysts and reagents to overcome such limitations have been continuously devoted.

\subsection{Auminum - Containing Reagents}

Recently, there have appeared a series of diisobutylaluminum derivatives, such as diisobutylhaloalanes (1),${ }^{[7-11]}$ diisobutylalkoxyalanes (2), ${ }^{[11-14]}$ diisobutylaminoalanes (3) ${ }^{[15-17]}$ diisobutylacetoxyalanes (4 and 5), ${ }^{[4]}$ and diisobutylmethanesulfonylalanes (6 and 7), ${ }^{[18-22]}$ which were prepared by simple reaction of diisobutylaluminum hydride (DIBAH) with the corresponding hydrogen halides, alcohols, amines, acetic acids, and methanesulfonic acids, respectively (Eq. 1-7). These diisobutylaluminum derivatives have achieved a very high chemo-, regio- and stereoselectivity in the reduction of aldehydes and ketones.

\subsection{Boron - Containing Reagents}

Generally, trialkylboranes are known to be tolerant to a wide variety of functional groups, ${ }^{[23]}$ but certain $\boldsymbol{B}$-R9-BBN, especially $\boldsymbol{B}$-Sia-9-BBN (8) is a mild chemoselective reducing agent for aldehydes. ${ }^{[4,5]}$

However, the first report on trialkylborane being capable of reducing both aldehydes and ketones under mild conditions appeared in $1985 .{ }^{24}$ Professor Brown and his coworkers devised diisopinocampheylchlorob- 


\begin{tabular}{|c|c|c|c|}
\hline $\begin{array}{l}i-\mathrm{Bu}_{2} \mathrm{AlH} \\
\text { (DIBAH) }\end{array}$ & + & $\mathrm{HX}$ & $\begin{array}{c}i-\mathrm{Bu}_{2} \mathrm{AlH} \\
1\end{array}$ \\
\hline$i-\mathrm{Bu}_{2} \mathrm{AlH}$ & + & $\mathrm{ROH}$ & $\begin{array}{c}i-\mathrm{Bu}_{2} \mathrm{AlH} \\
2\end{array}$ \\
\hline$i-\mathrm{Bu}_{2} \mathrm{AlH}$ & + & $\mathrm{R}_{2} \mathrm{NH}$ & $\begin{array}{c}i-\mathrm{B} \mathrm{u}_{\wedge} \mathrm{AlH} \\
3\end{array}$ \\
\hline$i-\mathrm{Bu}_{2} \mathrm{AlH}$ & + & $\mathrm{CH}_{3} \mathrm{COOH}$ & $\begin{array}{c}i-\mathrm{Bu}_{2} \mathrm{AlOAc} \\
4\end{array}$ \\
\hline$i-\mathrm{Bu}_{2} \mathrm{AlH}$ & + & $\mathrm{CF}_{3} \mathrm{COOH}$ & $\begin{array}{l}\frac{4}{i-\mathrm{Bu}_{2} \mathrm{AlO}_{2} \mathrm{CCF}_{3}} \\
\quad 5\end{array}$ \\
\hline$i-\mathrm{Bu}_{2} \mathrm{AlH}$ & + & $\mathrm{CH}_{3} \mathrm{SO}_{3} \mathrm{H}$ & $i-\mathrm{Bu}_{2} \mathrm{AlOSO}_{2} \mathrm{CH}$ \\
\hline$i-\mathrm{Bu}_{2} \mathrm{AlH}$ & + & $\mathrm{CF}_{3} \mathrm{SO}_{3} \mathrm{H}$ & $\begin{array}{c}i-\mathrm{Bu}_{2} \mathrm{AlOSO}_{2} \mathrm{CF}_{3} \\
\quad 7\end{array}$ \\
\hline
\end{tabular}<smiles>CC(C)C(C)B1C2CCCC1CCC2</smiles>

8

orane (Ipc 2 BCI) (9), which is the outcome from a strategic modification of the electronic and steric environments of the boron in trialkylboranes can reduce a variety of ketones as well as aldehydes to the corresponding alcohols even at $-25^{\circ} \mathrm{C}$. Soon other mono- and diisopinocampheylhaloboranes (10 and 11), were also prepared. ${ }^{[25-29]}$ Furthermore, hydroxy-, alkoxy-, acetoxyand methanesulfonyl-incorporated diisopinocampheylborane derivatives (12-17) were prepared and their applicability in MPV type reduction was explored. ${ }^{[30-36]}$

\subsection{Application for Organic Synthesis}

The MPV reduction is a classical but still widely used method for organic synthesis, because of high selectivity, relatively mild reaction conditions, simple and safe operations, and the low cost. In general, MPV reduction is performed with various catalyst and isopro-

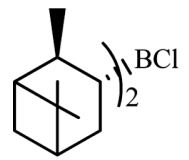

9<smiles>CC1(C)[C@H]2CC[C@@H]1C[C@H]2CO</smiles>

12

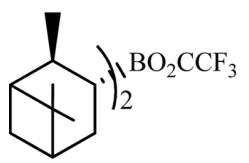

15

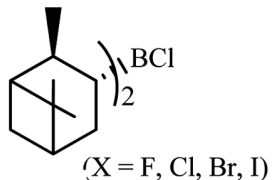

10

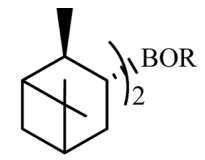

13

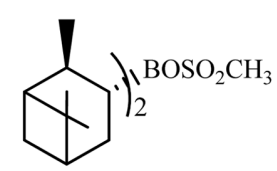

16

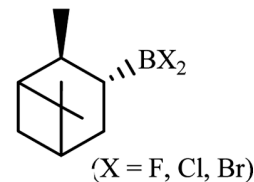<smiles>[AlH]</smiles><smiles>CC(=O)O[13C]1C2CC3C1[C@]2(C)C3(C)C</smiles>

14

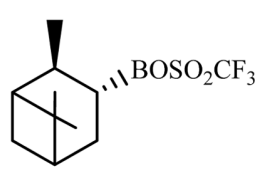

17

J. Chosun Natural Sci., Vol. 5, No. 2, 2012 
pyl alcohol as a hydride source; the mechanism can be described by the activation of the carbonyl group through its coordination to Lewis acidic metal site followed by reversible hydride transfer from alcoholate to the carbonyl acceptor via six-membered cyclic transition state as shown in Scheme 18 to 20. In this mechanistic point of view, the key step of this reaction must be the coordination of carbonyl oxygen to Lewis acidic metal site: without coordination of the substrate, no reduction takes place. Another characteristic feature of this reaction to be considered is the hydride-transfer pathway in which the reduction proceeds through the six-membered transition state. These combined characteristic features seem to play a major role performing an excellent selectivity in the MPV reductions, such as the following chemo, regio, and stereoselective reductions of carbonyl and epoxy compounds.

2.7. General Reducing Characteristics of Diisobutylaluminum and Diisopinocampheylboron Derivatives Toward Common Organic Functional Groups

Recently, the general reducing characteristics of diisobutylaluminum derivatives, such as $i-\mathbf{B u}_{\mathbf{2}} \mathbf{A I X}(\mathbf{1})$,

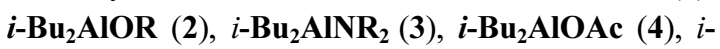
$\mathrm{Bu}_{2} \mathrm{AlO}_{2} \mathrm{CCF}_{3}(5), i-\mathrm{Bu}_{2} \mathrm{AlOSO}_{2} \mathrm{CH}_{3}(6), i-\mathrm{Bu}_{2} \mathrm{AlOSO}_{2}$ $\mathrm{CF}_{\mathbf{3}}$ (7), and diiopinocampheylboron derivatives, such as $\operatorname{Ipc}_{2}$ BX (10), Ipc $\mathbf{I}_{2}$ BOR (12 and 13), Ipc $\mathbf{I}_{2}$ BOAc (14), $\mathrm{Ipc}_{2} \mathrm{BO}_{2} \mathrm{CCF}_{3}$ (15), Ipc $\mathrm{AlOSO}_{2} \mathrm{CH}_{3}$ (16), and $\mathrm{Ipc}_{2}$ $\mathbf{A l O S O}_{2} \mathbf{C F}_{3}$ (17), have been examined systematically. After a broad examination and comparsion, some conclusions on the general reducing action of these derivatives toward organic functional groups have been drawn as follows:

(i) the relative reactivities of $\mathbf{I} \mathbf{p c}_{2} \mathbf{B X}$ series toward carbonyl compounds are in sequence of $\mathbf{I p c}_{2} \mathbf{B C l}>$
$\mathrm{Ipc}_{2} \mathrm{BF} \gg \mathrm{Ipc}_{2} \mathrm{BBr}>\mathrm{Ipc}_{2} \mathrm{BI}$,

(ii) the reactivity of $\operatorname{Ipc}_{2} \mathbf{B O R}$ (12 and 13) is much weaker than $\mathbf{I p c}_{2} \mathbf{B X}(\mathbf{1 0})$,

(iii) $\mathbf{I p c}_{2}$ BOR (12 and 13) can reduce aldehydes, but can not attack ketones,

(iv) the relative reactivities of $\boldsymbol{i}-\mathbf{B} \mathbf{u}_{2} \mathbf{A l}$-series are $\boldsymbol{i}$ -

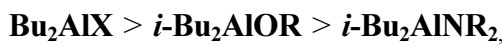

(v)the relative reactivities of $i$-B $\mathbf{u}_{2} \mathrm{AlOR}$ (2) series are $i$ - $\mathrm{Bu}_{2} \mathrm{AlOH}>i-\mathrm{Bu}_{2} \mathrm{AlOEt}>\boldsymbol{i}-\mathrm{Bu}_{2} \mathrm{AlO}^{i} \mathrm{Pr}>\boldsymbol{i}-\mathrm{Bu}_{2} \mathrm{AlO}^{t} \mathrm{Bu}$,

(vi) the reactivity of $\mathrm{Ipc}_{2} \mathrm{BO}_{2} \mathbf{C C F}_{3}$ (15), a fluorinated acetate derivative, is much higher than that of acetate derivative itself, $\mathbf{I p c}_{2} \mathbf{B O A c}$ (14),

(vii) the reactivity of $\mathrm{Ipc}_{2} \mathrm{AlOSO}_{2} \mathrm{CF}_{3}$ (17), a fluorinated sulfonated derivative, is much higher than that of sulfonate derivative itself, $\mathrm{Ipc}_{2} \mathbf{A l O S O}_{2} \mathbf{C H}_{3}$ (16).

As a result, the reactivity depends on what kind of moiety being attached to diisobutylaluminum or diisopinocampheylboron. Such reactivity difference may be attributed to the steric and electronic effects of the substituent. A relative reactivity toward organic functional groups is summarized in the Table 1 .

Most derivatives are reactive toward aldehydes and ketones, but quite inert to other functional groups including even acid chlorides. Especially noteworthy is that $\mathbf{I p c}_{2} \mathbf{B O H}$ appears the mildest one among the derivatives, exhibiting absolutely no reactivity toward every organic functional groups except aldehyde.

\subsection{Regioselective Ring-opening of Epoxide}

As expected for $\mathbf{S}_{\mathbf{N}} \mathbf{2}$ processes, nucleophilic hydride transferring reagents, such as $\mathrm{LiAlH}_{4}{ }^{[37]}$ and $\mathbf{L i E t}_{3} \mathbf{B H},{ }^{[38]}$ attack epoxides at the less substituted site to afford the more highly substituted alcohol.

On the other hand, with electrophilic hydride reagents such as $\mathrm{BH}_{3}{ }^{\left[{ }^{[9]}\right.}$ and $\mathrm{AlH}_{3}{ }^{[40]}$ reverse opening is often observed to produce the less substituted alcohol, but

Table 1. Comparison in Reactivity of Diisopinocampheylboron and Diisobutylaluminum Derivatives toward Common Organic Functional Groups ${ }^{\mathrm{a}}$

\begin{tabular}{|c|c|c|c|c|c|c|}
\hline \multirow{2}{*}{ Reagent type } & \multicolumn{6}{|c|}{ Organic functional groups } \\
\hline & aldehyde & ketone & ester & acid chloride & nitrile & epoxide \\
\hline Ipc $_{2} \mathrm{BX}$ & +++ & ++ & - & - & + & + \\
\hline $\mathbf{I p c}_{2} \mathrm{BOR}$ & ++ & - & - & - & - & - \\
\hline$i-\mathrm{Bu}_{2} \mathrm{AlX}$ & +++ & +++ & - & - & + & ++ \\
\hline$i-\mathrm{Bu}_{2} \mathrm{AlOR}$ & ++ & + & - & - & - & - \\
\hline$i-\mathrm{Bu}_{2} \mathrm{AlNR}_{2}$ & ++ & + & - & - & - & - \\
\hline
\end{tabular}

a+ Designates 'reactive', whereas designates 'inert'. 


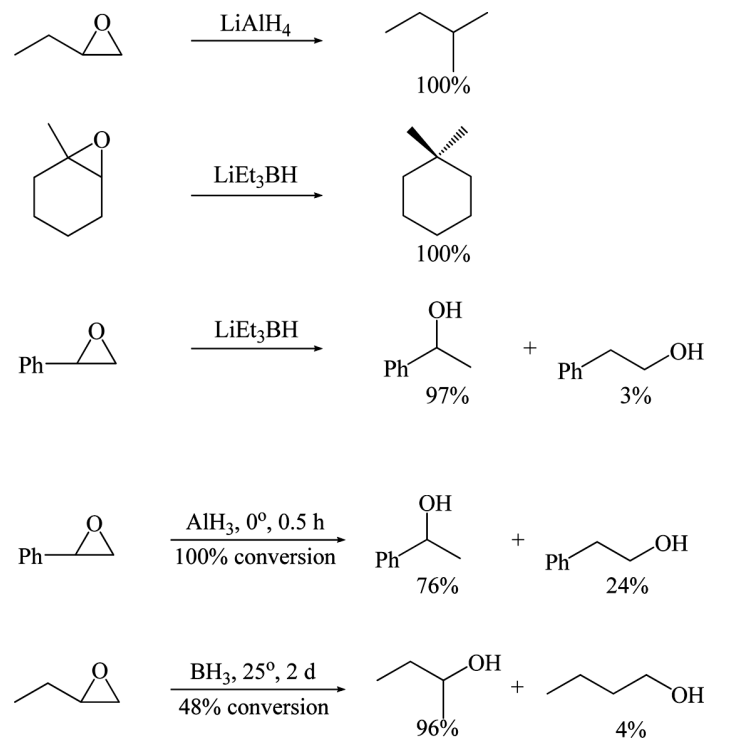

mixtures usually result.

However, activation of epoxide by complexation with a Lewis acid, and followed by nucleophilic attack with conventional mild metal hydrides has been demonstrated to be the most convenient and reliable process for producing predominately the less substituted alcohols. ${ }^{[41,42]}$ The addition of a Lewis acid not only accelerates the rate but also changes the products drastically. $\mathrm{BF}_{3}$ and $\mathrm{Ph}_{3} \mathrm{~B}$ are utilized as an efficient Lewis acid for such activation.

$$
\text { 要 } \stackrel{\mathrm{BF}_{3}}{\longrightarrow} \stackrel{\mathrm{NaBH}_{3} \mathrm{CN}}{\longrightarrow}
$$

The $\mathrm{BF}_{3}$ effect on the rate enhancement and hence the clean product formation has also been observed in the reduction of epoxides with $\mathrm{BH}_{3} \cdot{ }^{[43]}$ Thus, the reduction

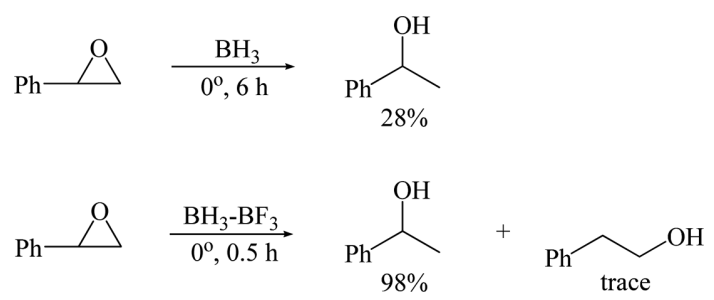

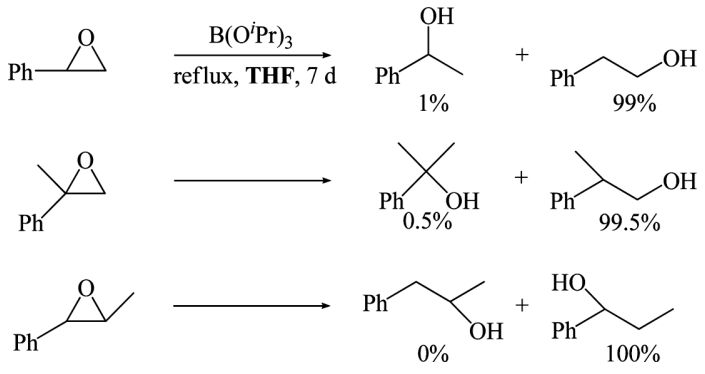

of styrene oxide with $\mathrm{BH}_{3}$ alone provides only $28 \%$ of the expected 2-phenylethanol at $0^{\circ} \mathrm{C}$ in 6 h. ${ }^{[39]}$ However, the presence of $\mathrm{BF}_{3}$ completely reduces styrene oxide at $0^{\circ} \mathrm{C}$ in less than $0.5 \mathrm{~h}$ to give a clean product.

The first report on the MPV type reduction of epoxides seems to be the communication which describes the reaction of epoxides with boron isopropoxide. ${ }^{[4]}$ The reagent is absolutely inert toward aliphatic epoxides such as 1,2-epoxybutane, 1,2-epoxyoctane and 1,2epoxycyclohexane even in refluxing THF for 7 days. On the other hand, the reaction of aromatic epoxides proceeds slowly in refluxing THF to produce exclusively the less substituted alcohols. In general, the reactivity of boron triisopropoxide is much milder than that of aluminum triisopropoxide: the reagent can reduce only aliphatic aldehydes and ketones. However, dichloroisopropoxyborane, a chlorine-incorporated boron alkoxide, shows a higher reactivity than that of boron triisopropoxide. ${ }^{[45]}$

The fluorine-incorporated diisobutylalane (DIBAF), one of the diisobutylhaloalane derivatives (1), exhibits a high reactivity toward various epoxides to complete the reduction in less than $24 \mathrm{~h}$ at $25^{\circ} \mathrm{C}$. Furthermore,

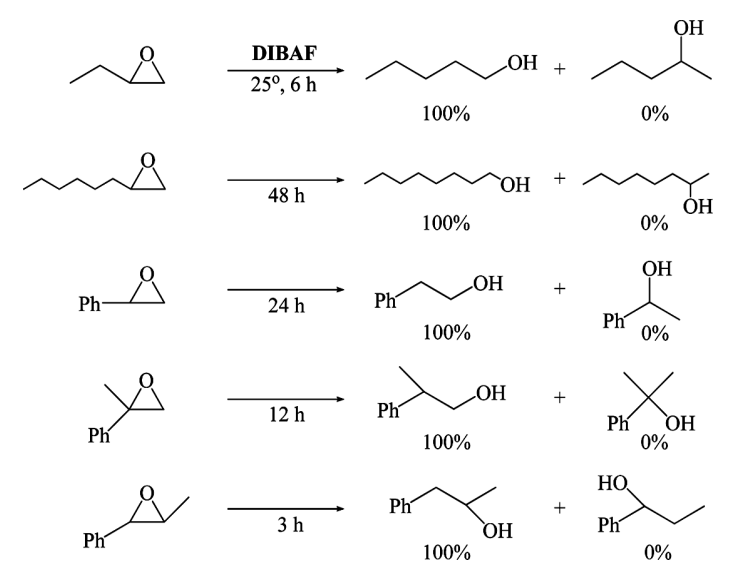

J. Chosun Natural Sci., Vol. 5, No. 2, 2012 
DIBAF achieves the regioselective cleavage of phenylor alkyl-substituted epoxides to the less substituted alcohols resulting from anti ring opening. Especially, the reagent attacks only at the phenyl-substituted site where both phenyl and alkyl groups are attached separately at each carbon site of epoxy ring. ${ }^{[46]}$

Similarly, the newly-devised acetoxy- and methanesulfonyl-substituted diisobutylalane derivatives, such as $\mathrm{Al}$-acetoxydiisobutylalane (DIBAOAc, 4), $\mathrm{Al}$ trifluoroacetoxydisiobutylalane (DIBAO $\left.\mathbf{C C F}_{3}, \mathbf{5}\right), \mathrm{Al}$ methanesulfonyldiisobutylalane (DIBAOSO${ }_{2} \mathrm{CH}_{3}, 6$ ), and Al-trifluoromethanesulfonyldiisobutylalane $\left(\mathbf{D I B A O S O}_{2}\right.$ $\mathbf{C F}_{3}, 7$ ), achieve the regioselective ring opening of epoxides. In general, the reactivity of fluorine-substi-

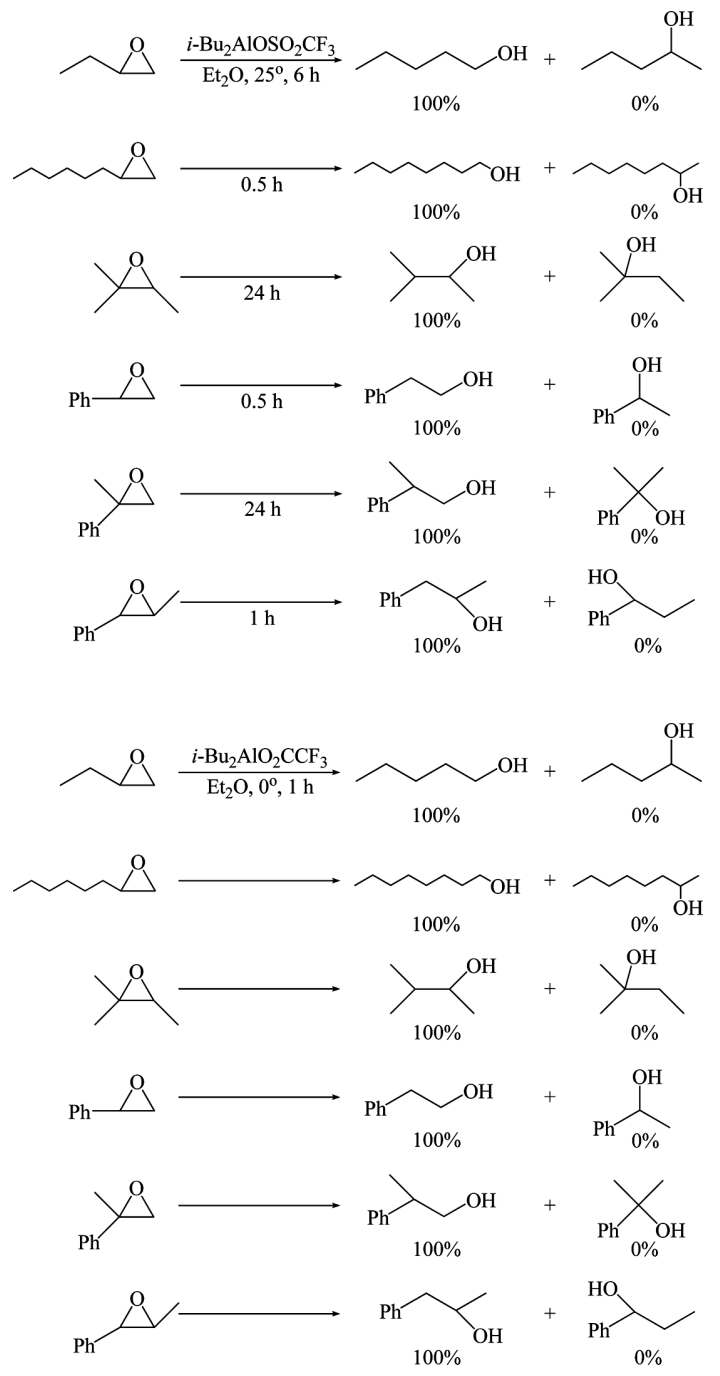

tuted derivatives are much higher than that of the parent unsubstituted derivatives. For example, DIBAOSO $\mathrm{CF}_{3}$ (7) can reduce a variety of aliphatic and aromatic epoxides readily at $25^{\circ} \mathrm{C}$ to the ring-opened alcohol products. ${ }^{[47,48]}$ In this reaction, the less substituted alcohols are produced as a sole product.

Especially noteworthy is that the results achieved by DIBAO $_{2} \mathbf{C C F}_{3}(\mathbf{5})^{[49]}$ : the ring-opening reaction is completed in less than $1 \mathrm{~h}$ at $0^{\circ} \mathrm{C}$.

It must be concluded that such a perfect regioselective ring-opening arises from the $\beta$-hydrogen transfer from the reagent only to the more positive carbon of the coordinated epoxy ring (Scheme 4).

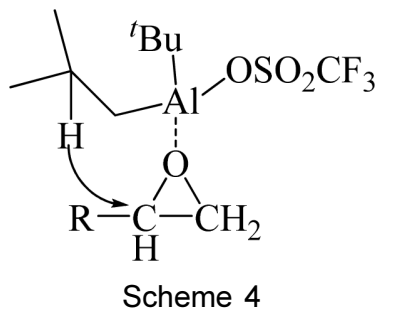

\section{Concluding Remarks}

The regiospecific ring-opening of unsymmetrical epoxides to the corresponding less substituted alcohols are of highly effective synthetic utility. Consequently, this review should provide a useful tool for organic chemists for such a purpose.

\section{References}

[1] H. I. Schlesinger, H. C. Brown, H. R. Hoekstra and L. R. Rapp, "Reactions of Diborane with Alkali Metal Hydrides and Their Addition Compounds. New Syntheses of Borohydrides. Sodium and Potassium Borohydrides1", J. Am. Chem. Soc. Vol. 75, p. $199,1953$.

[2] A. E. Finholt, A. C. Bond, Jr, and H. I. Schlesinger, "Lithium Aluminum Hydride, Aluminum Hydride and Lithium Gallium Hydride, and Some of their Applications in Organic and Inorganic Chemistry1", J. Am. Chem. Soc, Vol. 69, p. 1199, 1947.

[3] (a) B. M. Mikhailov, V. G. Kiselev, Y. N. Bubnov, Izv. AN SSSR, Ser. Khim, Vol. 898, 1965. (b) B. M. Mikhailov, Y. N. Bubnov and V. G. Kiselev, Zh. Obsh. Khim, Vol. 36, p. 62, 1965. 
[4] M. M. Midland, A. Tramontano and S. A. Zderic, "The facile reaction of B-alkyl-9-borabicyclo [3.3.1]nonanes with benzaldehyde", J. Organometal. Chem, Vol. 134, p. C17, 1977.

[5] M. M Midland and A. Tramontano, "B-Alkyl-9borabicyclo[3.3.1] nonanes as mild, chemoselective reducing agents for aldehydes" J. Org. Chem, Vol. 43, p. 1470, 1978.

[6] J. Chandrasekharan, P. V. Ramachandran and H. C. Brown, "Diisopinocampheylchloroborane, a remarkably efficient chiral reducing agent for aromatic prochiral ketones" J. Org. Chem, Vol. 50, p. 5446, 1985.

[7] J. S. Cha, O. O. Kwon, S. Y. Kwon, J. M. Kim, W. W. Seo and S. W. Chang, "Chemoselective Reduction of Carbonyl Compounds with Diisopinocampheylchloroborane", Synlett, Vol. 1055, 1995.

[8] J. S. Cha, O. O. Kwon and S. Y. Kwon, "Selective Reduction of á,â-Unsaturated Alde-hydes and Ketones to Allylic Alcohols with Diisobutylchloroalane", Bull. Korean Chem. Soc, Vol. 16, p. 1009, 1995.

[9] J. S. Cha, S. J. Park, S. J. Yu, S. K. Kim and O. O. Kwon, "Regioselective Cleavage of Phenyl- or Alkyl-Substituted Epoxides with Al-Fluorodiisobutylalane", Bull. Korean Chem. Soc, Vol. 29, p. 301, 2008.

[10] J. S. Cha and S. J. Park, "Selective Reduction of Orgainc Compounds with Al-Fluorodiisobutylalane", J. Chosun Natural Science, Vol. 2, p. 185, 2009.

[11] J. S. Cha, O. O. Kwon and S. Y. Kwon, "Selective Reduction of alpha,beta-Unsaturated Aldehydes and Ketones to Allylic Alcohols with Diisobutylalkoxyalanes", Org. Prep. Proced. Int, Vol. 28, No. 355, p. 116, 1996.

[12] J. S. Cha and O. O. Kwon, "Al-Isopropoxydiisobutylalane. A Stereoselective Reducing Agent for Reduction of Cyclic Ketones to Thermodynamically More Stable Alcohols", J. Org. Chem, Vol. 62, p. 3019, 1997.

[13] J. S. Cha and O. O. Kwon, "Reexamination of AlIsopropoxydiisobutylalane as a Stereoselective Reducing Agent for Reduction of Cyclic Ketones to Thermodynamically More Stable Alcohols", Bull. Korean Chem. Soc, Vol. 18, p. 689, 1997.

[14] J. S. Cha, O. O. Kwon, J. M. Kim, J. H. Chun, Y. S. Lee, H. S. Lee and S. D. Cho, "Selective Reduction of Carbonyl Compounds with Al-Alkoxydiisobutylalanes", Bull. Korean Chem. Soc, Vol. 19, p. 236, 1998.

[15] J. S. Cha, S. Y. Kwon, O. O. Kwon, J. M. Kim and
H. C. Song, "Selective Reduction of Carbonyl Compounds with Diisobutyldialkylaminoalanes", Bull. Korean Chem. Soc, Vol.17, p.900, 1996.

[16]. O. O. Kwon and J. S. Cha, "l-Pyrrolyldiisobutylalane. A Stereoselective Reducing Agent for Reduction of Cyclic Ketones to Thermodynamically More Stable Alcohols", Bull. Korean Chem. Soc, Vol.21, p.659, 2000.

[17]. J. S. Cha and K. W. Lee, "Reduction of Organic Compounds with Selective 1-Pyrrolyldiisobutyalane”, J. Natural Sciences, Vol. 22, p. 53, 2002.

[18] J. S. Cha and J. E. Yi, "Selective Reduction of Organic Compounds with Al-Trifluoroacetoxydiisobutylalane", J. Incl. Phenom. Macrocycl. Chem, Vol. 65, p. 15, 2009.

[19] J. S. Cha and S. J. Park, "Regioselective Ring Cleavage of Phenyl- or/and Alkyl- Substituted Epoxides with Al-Methanesulfonyldiisobutylalane", Bull. Korean Chem. Soc, Vol. 30, p. 2823, 2009.

[20] J. S. Cha and M. No, "Selective Reduction of Organic Compounds with Al-Methanesulfonyldiisobutylalane", Bull. Korean Chem. Soc, Vol. 31, p. 840, 2010.

[21] J. S. Cha and S. J. Park, "Regioselective Ring Cleavage of Phenyl- or/and Alkyl-Substituted Epoxides with Al-Trifluoromethanesulfonyldiisobutylalane. Comparison of Its Reactivity with AlMethanesulfonyldiisobutylalane", Bull. Korean Chem. Soc, Vol. 31, p. 2135, 2010.

[22] J. S. Cha, "Selective Reduction of Organic Compounds with Al-Trifluoromethanesulfonyl diisobutylalane. Comparison of Its Reactivity with AlMethanesulfonyldiisobutylalane", Bull. Korean Chem. Soc, Vol. 32, p. 219, 2011.

[23] H. C. Brown, G. W. Kramer, A. B. Levy and M. M. Midland, Organic Synthesis via Boranes, WileyInterscience: New York, 1975.

[24] (a) J. Chandrasekharan, P. V. Ramachandran and H. C. Brown, "Diisopinocampheyl chloroborane, a remarkably efficient chiral reducing agent for aromatic prochiral ketones" J. Org. Chem, Vol. 50, p. 5446, 1985. (b) H. C. Brown, W. S. Park, B. T. Cho and P. V. Ramachandran, "Selective reductions. 40. A critical examination of the relative effectiveness of various reducing agents for the asymmetric reduction of different classes of ketones" J. Org. Chem, Vol. 52, p. 5406, 1987.

[25] H. C. Brown, M. Srebnik and P. V. Ramachandran, "Chiral synthesis via organoboranes. 22. Selective reductions. 44. The effect of the steric requirements of the alkyl substituent in isopinocampheylalkyl- 
chloroboranes for the asymmetric reduction of representative ketones" J. Org. Chem, Vol. 54, p. 1577, 1989.

[26] H. C. Brown and P. V. Ramachandran, "Selective reductions. 45. Asymmetric reduction of prochiral ketones by iso-2-methyl-, iso-2-ethyl-, and [iso-2[2-(benzyloxy)ethyl]apopinocampheyl]-tert-butylchloroboranes. Evidence for a major influence of the steric requirements of the 2-substituent on the efficiency of asymmetric reduction", J. Org. Chem, Vol. 54, p. 4504, 1989.

[27] H. C. Brown, P. V. Ramachandran and J. Chandrasekharan, "Selective reductions. 56. Exploration of the B-haloisopinocampheylboranes for asymmetric reduction of ketones", Heteroatom Chem, Vol. 6, p. 117, 1995.

[28] J. S. Cha, E. J. Kim, O. O. Kwon and J. M. Kim, "Selective Reduction of Carbonyl Compounds with Diisopinocampheylhaloboranes", Bull. Korean Chem. Soc, Vol. 17, p. 50, 1996.

[29] J. S. Cha, O. O. Kwon, K. W. Lee and J. M. Kim, "Diisopinocampheylhaloboranes as Stereoselective Reducing Agents", Bull. Korean Chem. Soc, Vol. 26, p. 652, 2005.

[30] J. S. Cha, E. J. Kim, O. O. Kwon, S. Y. Kwon, W. W. Seo and S. W. Chang, "Transformation of Carboxylic Esters to Aldehydes with Sodium Tris(diethylamino)aluminum Hydride", Org. Prep. Proced. Int, Vol. 27, p. 541, 1995.

[31] J. S. Cha, E. J. Kim, O. O. Kwon and J. M. Kim, "B-t-Butoxydiisopinocampheylborane as a Highly Chemoselective Reducing Agent for Aldehydes", Bull. Korean Chem. Soc, Vol. 16, p. 691, 1995.

[32] J. S. Cha, O. O. Kwon and J. M. Kim, "Selective Reduction of Carbonyl Compounds with B-Alkoxydiisopinocampheylborane", Bull. Korean Chem. Soc, Vol. 17, p. 725, 1996.

[33] J. S. Cha, S. H. Jang, S. Y. Kwon and O. O. Kwon, "Selective Reduction of Carbonyl Compounds with BCyclohexoxydiisopinocampheylborane", Bull. Korean Chem. Soc, Vol. 25, p. 603, 2004.

[34] J. S. Cha, H. T. Nam, S. Y. Kwon, S. J. Park and O. O. Kwon, "Selective Reduction of Carbonyl Compounds with B-Phenoxydiisopinocampheylborane: Comparison of Its Reactivity to the Cyclohexoxy Derivative", Bull. Korean Chem. Soc, Vol. 25, p. 1948, 2004.

[35] J. S. Cha, H. T. Nam, S. J. Park, S. Y. Kwon and O. O. Kwon, "Selective Reduction of Carbonyl Compounds with B-Acetoxy- and B-Trifluoroacetoxydiisopinocampheylboranes”, Bull. Korean Chem.
Soc, Vol. 27, p. 667, 2006.

[36] J. S. Cha, "Selective Reduction of Carbonyl Compounds with B-Trifluoromethanesulfonyl diisopinocampheylborane in Ethyl Ether", Bull. Korean Chem. Soc, Vol. 30, p. 1658, 2009.

[37] H. C. Brown, P. M. Weissman and N. M. Yoon, "Selective Reductions. IX. Reaction of Lithium Aluminum Hydride with Selected Organic Compounds Containing Representative Functional Groups1", J. Am. Chem. Soc, Vol. 88, p. 1458, 1966.

[38] S. Krishnamurthy, R. M. Schubert and H. C. Brown, "Lithium triethylborohydride as a convenient reagent for the facile reduction of both hindered and bicyclic epoxides prone to electrophilically induced rearrangement", J. Am. Chem. Soc, Vol. 95, p. 8486, 1973.

[39] H. C. Brown, P. Heim and N. M. Yoon, "Selective reductions. XV. Reaction of diborane in tetrahydrofuran with selected organic compounds containing representative functional groups", J. Am. Chem. Soc, Vol. 92, p. 1637, 1970.

[40] (a) H. C. Brown and N. M. Yoon, "Selective Reductions. X. Reaction of Aluminum Hydride with Selected Organic Compounds Containing Representative Functional Groups. Comparison of the Reducing Characteristics of Lithium Aluminum Hydride and Its Derivatives", J. Am. Chem. Soc, Vol.88, p.1464, 1966. (b) N. M. Yoon and H. C. Brown, "Nuclear magnetic resonance spectra of fluorobenzenes. II. Effect of substituents on the meta and para fluorine-fluorine coupling constants", J. Am. Chem. Soc, Vol.90, No.2927, p.147, 1968. (c) R. O. Hutchins, I. M. Taffer and W. Burgoyne, "Regio- and stereoselective cleavage of epoxides with cyanoborohydride and boron trifluoride etherate", J. Org. Chem, Vol. 46, p. 5214, 1981.

[41] R. O. Hutchins, I. M. Taffer and W. Burgoyne, "Regio- and stereoselective cleavage of epoxides with cyanoborohydride and boron trifluoride etherate" J. Org. Chem, Vol. 46, p. 5214, 1981.

[42] N. M. Yoon and K. E. Kim, "Reaction of potassium triphenylborohydride with selected organic compounds containing representative functional groups", J. Org. Chem, Vol. 52, p. 5564, 1987.

[43] H. C. Brown and N. M. Yoon, "Reaction of diborane in tetrahydrofuran with styrene oxide and related epoxides in the presence of boron trifluoride. A convenient anti-Markovnikov reductive opening of such epoxides", Chem. Commun, Vol. 1549, 1968. 
[44] J. S. Cha and J. H. Park, "Reaction of Epoxides with Boron Triisopropoxide.The Meerwein-PonndorfVerley Type Reduction of Boron Alkoxides.21", Bull. Korean Chem. Soc, Vol. 23, p. 1377, 2002.

[45] J. S. Cha, S. J. Yu, M. Y. Roh, S. J. Park, E. J. Yi and O. O. Kwon, "Reaction of Aldehydes and Ketones with Dichloroisopropoxyborane. Comparison of the Reducing Characteristics of Isopropoxyborane Derivatives", Bull Korean Chem. Soc, Vol. 29, p. 885, 2008.

[46] (a) J. S. Cha, S. J Park, S. J. Yu, S. K. Kim and O. O. Kwon, "Regioselective Cleavage of Phenyl- or Alkyl-Substituted Epoxides with Al-Fluorodiisobutylalane", Bull. Korean Chem. Soc., Vol. 29, p. 301, 2008. (b) J. S. Cha and S. J. Park, "Selective Reduction of Orgainc Compounds with Al-Fluorodiisobutylalane", J. Chosun Natural Science, Vol. 2, p. 185, 2009.
[47] J. S. Cha and S. J. Park, "Regioselective Ring Cleavage of Phenyl- or/and Alkyl-Substituted Epoxides with Al-Trifluoromethanesulfonyldiisobutylalane. Comparison of Its Reactivity with AlMethanesulfonyldiisobutylalane", Bull. Korean Chem. Soc, Vol. 31, p. 2135, 2010.

[48] J. S. Cha, "Selective Reduction of Organic Compounds with Al-Trifluoromethanesulfonyldiisobutylalane. Comparison of Its Reactivity with AlMethanesulfonyldiisobutylalane", Bull. Korean Chem. Soc, Vol. 32, p. 219, 2011.

[49] J. S. Cha and J. E. Yi, "Selective Reduction of Organic Compounds with Al-Trifluoroacetoxydiisobutylalane", J. Incl. Phenom. Macrocycl. Chem, Vol. 65, p. 15, 2009. 